\title{
PÓS-DOUTORADO E O CENÁRIO DOS RESULTADOS NA CARREIRA DOCENTE: UMA ANÁLISE DA ÁREA DE PSICOLOGIA
}

Marcello Vinicius Dória Calvosa

Universidade Federal Rural do Rio de Janeiro - UFRRJ
Recebido em: 16/04/2019

$1^{\text {a }}$ revisão em: 20/01/2020

Aceito em: 09/02/2020

\section{RESUMO}

O artigo buscou investigar o pós-doutorado na área de Psicologia e responder as seguintes questões: O pós-doutorado influencia ou não na carreira docente no sentido dos seus outputs? O pós-doutorado na área da Psicologia produz efeitos tais como nas demais áreas? Com amostra constituída por 350 docentes da área e que integraram o quadro permanente da pós-graduação stricto sensu, foram analisados os seguintes aspectos: Trajetória de formação; tempo de carreira; realização ou não de pós-doutorado; nota do programa de pós-graduação; produção de artigos e participação em comitê editorial de periódicos estrato 'A'. Principais resultados: Para os recém-doutores a realização de pós-doutorado não afeta a produção científica, mas influencia nas chances de participar de comitê editorial de um periódico internacional; e, os outputs do pós-doutorado no geral são mais expressivos para os doutores seniores para os quais o estágio pósdoutoral mostrou ser um fator diferenciador das suas médias de produção científica.

Palavras-chave: psicologia; pós-doutorado; qualificação docente; carreira. 


\section{POSTDOCTORAL RESEARCH AND THE OUTPUTS SCENARIO AT PROFESSOR'S}

\section{CAREER: AN ANALYSIS OF THE PSYCHOLOGY AREA}

\section{ABSTRACT}

The paper sought to investigate the postdoctoral research at area of Psychology and answer the following questions: Does the post-doctorate degree influence or not the professor career at sense of its outputs? Postdoctoral research in psychology produces effects such as in other areas? With a sample of 350 graduate professors who integrated the permanent framework of the graduate studies, the following aspects were analyzed: Academic trajectory; realization of post-doctoral research or not; articles published in periodicals of international level; graduate program score and the participation in editorial committee at journals of international standard. Some results found: Among junior doctors the completion of postdoctoral studies does not affect your scientific production, but influences the chances of participating in an international journal editorial committee and the results of postdoctoral research are more expressive for the senior doctors for whom the post-doctorate showed to be a differential factor to their scientific production averages.

Keywords: psychology; postdoctoral research; professor qualification; career. 


\section{PASANTÍA POSTDOCTORAL Y EL ESCENARIO DEL RESULTADOS EN LA CARRERA DEL PROFESOR: UNA ANÁLISIS DE LA ÁREA DE PSICOLOGÍA}

\section{RESUMEN}

El artículo buscó investigar la etapa de post-doctorado en la área de Psicología y responder las siguientes preguntas: ¿Influye o no la etapa del post-doctorado en la carrera del profesor en el sentido de sus resultados? ¿La etapa de postdoctorado en psicología produce efectos como en otras áreas? Con muestra de 350 profesores actuantes en posgrado, se analizaron los aspectos: Trayectoria académica; realización o no de la etapa de post-doctorado; artículos publicados en revistas de nivel internacional y la participación en el comité editorial en revistas internacionales. Resultados encontrados: Entre recién doctores, la finalización de los estudios postdoctorales no afecta su producción científica, pero influye en las posibilidades de participar en un comité editorial de una revista internacional y los resultados son más expresivos para los profesores con mayor tiempo de carrera para los cuales la etapa de post-doctorado demostró ser un factor diferencial a sus promedios de producción científica.

Palabras clave: psicología; pasantía postdoctoral; cualificación docente; carrera. 


\section{INTRODUÇÃO}

Castro e Porto (2016) trazem para o cenário da pesquisa acadêmica, uma realidade pós-doutoral vivida pelos docentes universitários, em que, parcimoniosamente, os poucos estudos existentes sobre o fenômeno pósdoutoral tentam abarcar a realidade do pós-doutorado vivenciada pelos docentes com o foco exclusivo na avaliação da sua possível influência sobre a produção científica e/ou bibliográfica.

Reconhecendo que as pesquisas deveriam também direcionar esforços para ampliar o escopo, indo para além da pesquisa (e seus outputs), para outros aspectos do ensino e extensão, que também estão presentes na pós-graduação, Castro e Porto (2016) realizam críticas amplas ao atual [restrito] modelo ou esse paradigma atual de investigação. Na ampla revisão sobre o tema do pósdoutorado, realizado pelos autores, chama a atenção o fato de que a área de Psicologia não é contemplada pelas investigações.

Como, certamente, o fenômeno da capacitação por meio dos estágios pósdoutorais é uma realidade também na área de Psicologia, sem dúvidas, emerge a situação emblemática que no cenário das atuais pesquisas científicas não se busca abordar a influência ou o impacto do pós-doutorado na área de Psicologia como um todo, sendo portanto uma grande lacuna a ser investigada.

O pós-doutorado realizado na área de Psicologia produz efeitos tais como nas demais áreas? Essa é a primeira pergunta a ser equacionada. Autores como Coraiola, Baratter, Takahashi e May (2013) sentindo que o levantamento de Castro, Porto e Kannebley (2013) traz um cenário instigante para pesquisa, mas deixa em aberto diversas áreas, em especial as áreas de Humanas e Sociais Aplicadas, resolveram realizar um mapeamento inicial e uma pesquisa no sentido de investigar o perfil dos docentes e o cenário do pós-doutorado na área de Administração.

Sobre a questão das áreas do conhecimento tem-se apenas trabalhos como os de Coraiola et al. (2013), que levantam brevemente a questão do perfil dos docentes que resolvem realizar pós-doutorado na área de Administração e há também o artigo de Castro e Porto (2010), o qual encontra o resultado de que no que diz respeito aos resultados do pós-doutorado não existe heterogeneidade entre grandes áreas do conhecimento.

Vale ressaltar que o trabalho de Castro e Porto (2010) limita-se a focar às grandes áreas de Biológicas, Exatas e da Terra, Engenharias e Ciências da Saúde. Nessas quatro áreas do conhecimento o pós-doutorado mostrou-se 'não heterogêneo' trazendo na USP resultados muito parecidos, não se diferenciando entre si essas grandes áreas consideradas de 'Hard Sciences'. 
Da mesma forma há como justificativa, para este atual artigo, esse sentir que a área de Psicologia merece e pode ser investigada. Os estudos até então presentes na literatura investigaram o impacto do pós-doutorado no sentido institucional:

a) Investigação do pós-doutorado na Universidade de São Paulo - USP (Castro \& Porto, 2008, 2012; Castro, 2017; Castro et al., 2013); e

b) Investigação do pós-doutorado na Universidade Federal Fluminense - UFF (Calvosa, Repossi, \& Castro, 2011).

Com esse recorte nessa pesquisa - com um foco mais transversal, ou seja, com o focar a área do conhecimento e não a instituição, muda-se a perspectiva; estando inclusive plenamente em acordo com o exposto em Castro e Porto (2016, p. 182) em que: "no momento, a julgar pelo estado da arte, há muito a se fazer".

No mesmo caminho de todos os argumentos expostos em Castro e Porto (2016) sobre pós-doutorado, sua importância e também até em alguns casos a sua 'supervalorização', que em algumas situações, o torna de forma subjetiva praticamente obrigatório uma etapa que deveria per si um estar complementar e com caráter opcional por excelência. A esse respeito, também Mueller (2006) destaca que "a comunidade científica não existe em um vácuo social, mas é um dos muitos grupos sociais que compõem a sociedade contemporânea" (p. 31).

Para Mueller (2006) a questão fundamental para um país em desenvolvimento, no que diz respeito à formação de recursos humanos de alto nível, está no dimensionamento do apoio dessa formação com recursos públicos, considerando também o adequado aproveitamento desse contingente, destacando-se que o acesso à informação, inclusive informação científica, torna-se cada vez mais dinâmico com as novas tecnologias, portanto havendo cada vez mais a possibilidade de acesso e de reciclagem profissional de uma forma autônoma e/ou a distância.

O pós-doutorado é essencialmente um 'aperfeiçoamento profissional' por meio da socialização entre docentes (Castro, 2017), em outras palavras, o pósdoutorado é uma atividade de qualificação de essência presencial e não de interação entre pesquisadores à distância. Isso por sua vez, apenas aumenta a importância das investigações de impacto dessas atividades, para melhor aproveitamento desses contingentes, financeiros e humanos envolvidos no processo de interação acadêmica entre pesquisadores doutores.

A ideia de que o pós-doutorado deve ser opcional na carreira de um docente pode ser observada pelo ponto de vista de lógica da racionalidade administrativa ou até do bom senso - tendo-se em perspectiva que, o professor universitário, qualificado em nível da titulação de doutorado, é um pesquisador-docente pleno do ponto de vista das suas competências. No entanto, a depender das peculiaridades da sua atuação, em vista da rápida e cada vez mais dinâmica 
produção do conhecimento científico contemporâneo pode necessitar de atualização de tempos em tempos, de uma forma continuada, ajudando em seu desenvolvimento de carreira.

Além dessa questão que poderia intitular-se de bom senso para alguns, a 'não obrigatoriedade' do pós-doutorado para a atuação docente, com a visão de que capacitação via estágio pós-doutoral age, enquanto peça recente na engrenagem universitária, especialmente no subsistema da pós-graduação, sendo um componente opcional para a carreira acadêmica, está fortemente alicerçada em dados empíricos no trabalho constante em Castro et al. (2013) verificando a situação pós-doutoral vivenciada pelos professores da Universidade de São Paulo (USP) e também foi corroborada pelo levantamento censitário realizado por Calvosa et al. (2011), na Universidade Federal Fluminense (UFF).

Como contraponto a esse modelo de busca de atualização docente especialmente com estágio no exterior - e que pode ser mais fortemente aplicável nas áreas de Sociais Aplicadas e de Humanas, no nível da práxis, Trigueiro (2001, p. 65) entende que "a principal necessidade para a formação dos cientistas contemporâneos é a ampliação considerável da comunicabilidade, em suas diferentes formas, níveis e processos, para o cotidiano desses profissionais".

Dos pontos destacados por Trigueiro (2001) acerca da capacitação dos cientistas sobressai-se para o autor a necessidade de uma visão e de uma prática que considerem um olhar estratégico, propiciando a prática do planejamento e da avaliação, assim como o estímulo à criatividade, favorecendo novas iniciativas. $E$ adverte que, sobretudo (p. 68): "No contexto latino-americano, precisamos estimular a busca de resultados e de esforços que não se limitem ao padrão dominante da ciência em nível mundial".

A produtividade científica é entendida por Bonaccorsi e Daraio (2003) como a relação entre outputs de pesquisa científica e seus inputs, sendo um dos outputs a publicação científica. Isto é, a mesma concepção e a mesma direção do exposto em Castro e Porto (2016), sobre a relação entre a socialização e externalização científica sobre a ótica da gestão do conhecimento. Em síntese, o olhar da racionalidade administrativa em ambos os estudos citados tende a considerar na relação de produtividade, os insumos e o investimento para o desenvolvimento da pesquisa, considerados inputs (fatores extrínsecos) da política científica, que envolve as linhas de pesquisa, os recursos humanos, o suporte logístico, a execução da pesquisa, as comunidades de práticas, os grupos, as redes e os diversos procedimentos para realizar outputs (difusão dos resultados da pesquisa).

Nos outputs do pós-doutorado, dentre diversos indicadores possíveis, podem ser considerados: a produção científica, a sua visibilidade, a qualidade do ensinopesquisa-extensão no cenário ex post, a atualização profissional e, também, diversos aspectos relacionados com a cienciometria com seus indicadores de produtividade e impacto. 
Meneghini (1995), investigando os outputs de diversas áreas de pesquisa, levanta a tese de que o doutorado pleno no exterior só deveria ser realizado em casos excepcionais, pois os que se titularam no exterior publicam em nível praticamente igual ao dos titulados no Brasil. No entanto, Castro e Porto (2012) demostram que, embora o doutorado realizado no Brasil mostre outputs nos mesmos níveis que os realizados no Exterior, o pós-doutorado realizado fora do país tende a mostrar um impacto relevante sobre a produção em periódicos internacionais padrão ' $A$ ', podendo também conforme destacam Castro e Porto (2008), inclusive valer a pena um segundo retorno ao exterior, isto é, um docente com doutorado pleno no exterior e com estágio de treinamento pós-doutoral, também no exterior.

A relevância do foco na produção científica é destacada na obra de Witter (1996) quando a conceitua como a forma pela qual a universidade ou instituição de pesquisa se faz presente no saber-fazer-poder-ciência; por ser inegável o papel da ciência na vida das pessoas, das instituições, dos países. Pode-se afirmar que na apresentação do aspecto 'ensino-pesquisa', a produção científica está ligada à maioria das coisas, dos eventos, das atividades da pós-graduação e de várias proposições acadêmicas cotidianas.

Em um cenário bem diverso, atualmente, considerando-se a grande área de Ciências Humanas, a Psicologia, com 94 programas ativos, está entre as que possuem mais cursos em nível de pós-graduação. No Documento de Área referente ao ano de 2017 [disponível no website www.capes.gov.br], a Comissão da Capes realizou as seguintes recomendações: incentivar um maior intercâmbio entre programas e pesquisadores, em âmbito nacional e também internacional, assim como investir na produção bibliográfica, dando prioridade à publicação em periódicos qualificados.

Essas recomendações também estavam presentes no relatório do Documento de Área do ano de 2004 e das avaliações trienais subsequentes. O que leva a entender que a pós-graduação em Psicologia, nos últimos anos, teve intensa consolidação, que pode ser percebida, entre outros fatores, pela ampliação das demandas por financiamento em diferentes instâncias.

Macedo e Sousa (2010) apontam que do ponto de vista da ampliação do sistema de pós-graduação, os dados são tão promissores que, por causa disso, ao menos na grande área de Humanas na área de Educação, parece que se está atingindo a uma certa saturação. A capacidade de criação de novos cursos de mestrado vemse reduzindo e concentrando-se em universidades privadas. No nível de doutorado ainda há alguma margem de crescimento, mas em geral, os cursos novos contam com um quadro reduzido de docentes, o que deve dificultar-lhes atingir níveis de excelência. Parece que estamos, segundo as autoras, num momento em que é fundamental projetar estratégias para a continuidade da ampliação quantitativa e qualitativa da pós-graduação. 
O pós-doutorado pode atuar como alavancador de carreira docente para a excelência na pós-graduação? Com essa pergunta emblemática a pesquisa buscou investigar a seguinte questão de pesquisa: Docentes da Psicologia com pós-doutoramento no exterior publicam mais artigos em periódicos de padrão internacional? Também, as seguintes perguntas secundárias: Esses docentes têm maior nível de participação em comitês de periódicos desse padrão, do que docentes sem pós-doutorado? O pós-doutorado na área da Psicologia contribui enquanto qualificação docente e desenvolvimento de carreira nesse sentido dos seus outputs?

\section{MÉTODO}

A população da pesquisa foi constituída pelos docentes da pós-graduação Stricto Sensu brasileira que, segundo informações fornecidas pela Capes, integraram o quadro permanente dos diversos programas de pós-graduação no de 2016, na área de Psicologia.

Inicialmente solicitou-se à Capes uma listagem de docentes do universo dos que atuavam como professor permanente na pós-graduação. Tendo como referência o ano de 2016 foram solicitados dados referentes à sua titulação, instituição de atuação acadêmica, publicações conforme o Qualis da área e outras variáveis. O universo da área conteve então, 4.826 docentes da Psicologia, resumido conforme Tabela 1.

Devido ao tempo despendido na obtenção dos dados e em função dos escassos recursos humanos, econômicos e de tempo, apesar de reconhecer a supremacia de um estudo censitário como o proposto em Calvosa et al. (2011), foi necessário ter-se que pesar o grande número de docentes, sobretudo após verificação de que os dados de produção enviados eletronicamente pela Capes estavam muitas vezes desatualizados em relação à produção bibliográfica do docente (tendo em vista que a avalição quadrienal somente ocorreria em 2017, o que por sua vez aumenta a preocupação em relação à fidedignidade do sistema Lattes do CNPq e a sua alimentação no sistema (Coleta da Capes), tornando-se necessário uma apreciação individualizada e busca no sistema Lattes on-line. Frente aos fatos, um estudo censitário poderia tornar-se operacionalmente dificultado.

Para fins desta pesquisa, sendo considerado o interstício (intervalo de tempo) entre a titulação de doutorado e a realização do pós-doutorado definiu-se como doutor júnior, o doutor recém-titulado ou ainda com no máximo cinco anos de titulação; e, doutor sênior como sendo aquele com mais de cinco anos de titulação. 
Tabela 1

Distribuição dos docentes na pós-graduação da área de Psicologia

\begin{tabular}{|c|c|c|c|c|}
\hline $\begin{array}{l}\text { Área do Programa de } \\
\text { Pós-Graduação }\end{array}$ & $\begin{array}{l}\text { Professor } \\
\text { Colaborador }\end{array}$ & $\begin{array}{l}\text { Professor } \\
\text { Permanente }\end{array}$ & $\begin{array}{l}\text { Professor } \\
\text { Visitante }\end{array}$ & $\begin{array}{l}\text { Total de } \\
\text { docentes }\end{array}$ \\
\hline $\begin{array}{c}\text { Psicologia Experimental } \\
\text { e Análise do } \\
\text { Comportamento }\end{array}$ & 62 & 318 & 23 & 403 \\
\hline Psicologia da Linguagem & - & 71 & - & 71 \\
\hline $\begin{array}{l}\text { Mestrado Profissional } \\
\text { em Atenção Psicossocial }\end{array}$ & 3 & 16 & - & 19 \\
\hline $\begin{array}{l}\text { Neurociências e } \\
\text { Comportamento }\end{array}$ & 67 & 191 & 12 & 270 \\
\hline $\begin{array}{l}\text { Práticas e Inovação em } \\
\text { Saúde Mental }\end{array}$ & 2 & 20 & 4 & 26 \\
\hline $\begin{array}{l}\text { Processos de } \\
\text { Desenvolvimento } \\
\text { Humano e Saúde }\end{array}$ & 18 & 147 & - & 165 \\
\hline Psicanálise & 50 & 224 & 15 & 289 \\
\hline Psicobiologia & 76 & 182 & - & 258 \\
\hline Psicogerontologia & 7 & 28 & 4 & 39 \\
\hline Psicologia & 221 & 2155 & 79 & 2455 \\
\hline Psicologia Clínica & 119 & 322 & 12 & 453 \\
\hline Psicologia Cognitiva & 29 & 120 & 1 & 150 \\
\hline Psicologia da Saúde & 34 & 175 & - & 209 \\
\hline $\begin{array}{l}\text { Psicologia do } \\
\text { Desenvolvimento e } \\
\text { Aprendizagem }\end{array}$ & 17 & 138 & - & 155 \\
\hline $\begin{array}{l}\text { Psicologia Escolar } \\
\text { /Educacional }\end{array}$ & 54 & 210 & - & 264 \\
\hline $\begin{array}{c}\text { Psicologia } \\
\text { Organizacional e do } \\
\text { Trabalho }\end{array}$ & 77 & 197 & 1 & 275 \\
\hline Psicologia Social & 94 & 248 & 36 & 378 \\
\hline $\begin{array}{c}\text { Psicossociologia de } \\
\text { Comunidades e Ecologia } \\
\text { Social }\end{array}$ & 21 & 64 & 1 & 86 \\
\hline Total & 951 & 4826 & 188 & 5965 \\
\hline
\end{tabular}


Os estratos amostrais foram definidos a partir do nível de experiência quando da realização do pós-doutorado e o locus da formação doutoral. Assim, o universo da área foi dividido em seis estratos, a saber:

- Júnior com titulação de doutorado no exterior;

- Júnior com titulação de doutorado no País;

- Sênior com titulação de doutorado no exterior;

- Sênior com titulação de doutorado no País; e,

- Juniores e seniores que fizeram doutorado sanduíche.

Para tratar os dados foram utilizadas as técnicas de análise univariada (tabela simples), bivariada (tabela cruzada) e bivariada com controles (tabela múltipla). Os resultados obtidos são apresentados sob a forma de gráficos e tabelas. A tabulação dos dados foi realizada utilizando o software de pacote estatístico SPSS (Statistical Package for the Social Sciences).

Para cada tipo de análise considerou-se a trajetória de formação dos sujeitos, comparando-se os juniores e seniores (nível de experiência acadêmica), ou tecnicamente nos casos dos com pós-doutorado equivale ao (I) interstício [i.e. intervalo de tempo] transcorrido entre a conclusão do doutorado e a realização do pós-doutorado no exterior, o (II) local da titulação, considerando-se os doutores que se titularam no Brasil, os que se titularam no exterior e os docentes que quando da formação de doutorado fizeram um breve estágio no exterior (doutorado sanduíche).

Além dessas variáveis também foi verificado se o docente realizou ou não realizou pós-doutorado e a instituição universitária em que atua o docente foi considerada e classificada para fins de pesquisa, segundo a nota do programa na avaliação realizada pela Capes referente ao desempenho do programa de pósgraduação no triênio período 2010-2013 e, assim, os cruzamentos de dados entre essas diversas variáveis independentes foram efetuados.

O levantamento de informações efetuado no Currículo Lattes, além de identificar artigos publicados em periódicos de nível internacional, acompanhando a literatura científica acerca do pós-doutorado, adicionalmente buscando alargar critérios de investigação, inicialmente teve por objetivo coletar os dados quanto a outras possibilidades referentes a aspectos da inserção internacional: (I) a participação em comitê editorial de revista de padrão internacional e (II) a prestação de consultoria a agência internacional de fomento.

Quanto à participação em comitê editorial de revista de padrão internacional (A1 e A2), cada participação registrada deveria se referir a um único periódico, não importando o número de anos em que o docente integrou o comitê. 
Quanto à consultoria, a agência internacional de fomento, a proposta inicial era debruçar-se sobre mais essa questão como possível variável relativa a aspectos da inserção internacional do docente, após a realização do pós-doutorado. Entretanto, na medida em que a análise de dados transcorria foi preciso reconsiderar essa decisão, pois seria necessário identificar, em cada Currículo Lattes, se a agência internacional informada era de fomento ou organismo multilateral que com frequência encomenda/financia estudos e, por esse motivo, pode ser considerada análoga àquela, com impactos na questão operacional de pesquisa.

Essa verificação traria enormes dificuldades quanto a execução da pesquisa, como exemplificados a seguir: • O Banco Mundial e o BID (Banco Interamericano para o Desenvolvimento) frequentemente encomendam consultorias (estudos) de seu interesse, mas não são propriamente agências internacionais de fomento. ' A National Science Foundation (NSF), dos Estados Unidos, tem corpo científico próprio, publica um amplo leque de estatísticas sobre o destino profissional de doutores e outros assuntos relativos a temas de Ciência e Tecnologia, e é a maior agência de fomento à pesquisa daquele país em várias áreas, como Saúde e Estudos Sociais da Ciência.

Essa fundação não é propriamente uma agência internacional de fomento, que está voltada unicamente para os Estados Unidos. Entretanto, se algum grupo de pesquisa internacional (em rede) obtém recursos da NSF, pode considerar que está tendo financiamento internacional de fomento de primeira linha, e altamente competitivo.

A Organização Internacional do Trabalho (OIT) - no sentido inverso da NSF mantém escritórios em um grande número de países, inclusive no Brasil, não sendo propriamente uma agência internacional de fomento à pesquisa. Ela possui capital intelectual próprio (sobretudo doutores em Economia), mas publica com frequência boletins e estudos de caráter regional (Brasil ou América Latina, por exemplo) e de caráter internacional sobre questões como emprego, trabalho e políticas de emprego e renda.

O trabalho de identificar uma consultoria a uma agência de fomento internacional, como se observa, seria bastante complexo, em especial se considerando a perspectiva de se trabalhar com dados secundários a partir do Currículo Lattes, no qual não há um campo específico para a inclusão dessa informação de maneira estruturada.

Assim, de fato, apesar do intuito de alargar-se bem mais as variáveis que constam da literatura acerca do impacto do pós-doutorado, foram trabalhadas enquanto variável original dessa pesquisa, a participação em comitê editorial de revista de padrão internacional. Que é, não necessariamente, um output do processo de pós-doutorado, mas um incremento de qualidade no que diz respeito ao escopo de atuação do docente. 
Tabela 2

Características dos doutores na amostra - em termos percentuais $(n=350)$

\begin{tabular}{|c|c|c|c|c|}
\hline \multirow{2}{*}{ Variável } & \multirow{2}{*}{ Categorias } & \multicolumn{2}{|c|}{$\begin{array}{l}\text { Nível de Experiência } \\
\text { (tempo de carreira) }\end{array}$} & \multirow{2}{*}{ Geral } \\
\hline & & Júnior & Sênior & \\
\hline \multirow{2}{*}{ Sexo (\%) } & Feminino & 65,1 & 46,6 & 54,8 \\
\hline & Masculino & 34,9 & 53,4 & 46,2 \\
\hline \multirow{2}{*}{$\begin{array}{l}\text { Pós-Doutorado } \\
\text { realizado (\%) }\end{array}$} & Não & 74,0 & 63,2 & 68,1 \\
\hline & Sim & 26,0 & 36,8 & 31,9 \\
\hline \multirow{3}{*}{$\begin{array}{c}\text { Local da } \\
\text { Titulação do } \\
\text { Doutorado (\%) }\end{array}$} & Brasil & 85,6 & 74,1 & 79,5 \\
\hline & Exterior & 8,2 & 25,3 & 17,5 \\
\hline & $\begin{array}{c}\text { Dout. no país com } \\
\text { estágio no exterior } \\
\text { (sanduíche) }\end{array}$ & 6,2 & 0,6 & 3,1 \\
\hline \multirow{2}{*}{$\begin{array}{l}\text { Local do Pós- } \\
\text { Doutorado (\%) }\end{array}$} & Brasil & 47,4 & 23,4 & 32,4 \\
\hline & Exterior & 52,6 & 76,6 & 67,6 \\
\hline \multirow{5}{*}{$\begin{array}{c}\text { Nota do } \\
\text { programa em } \\
\text { que atua (\%) }\end{array}$} & 3 & 15,1 & 11,5 & 13,1 \\
\hline & 4 & 49,3 & 37,3 & 46,2 \\
\hline & 5 & 22,6 & 28,2 & 25,6 \\
\hline & 6 & 6,2 & 9,2 & 7,8 \\
\hline & 7 & 6,9 & 13,8 & 7,3 \\
\hline $\begin{array}{l}\text { Publicou ao } \\
\text { menos um } \\
\text { artigo em } \\
\text { revista de }\end{array}$ & Sim & 27,4 & 39,9 & 34,2 \\
\hline \multicolumn{5}{|l|}{$\begin{array}{l}\text { 'A', ao longo da } \\
\text { carreira (\%) }\end{array}$} \\
\hline Participa(ou) de & Sim & 3,4 & 1,2 & 2,2 \\
\hline $\begin{array}{c}\text { internacional } \\
(\%)\end{array}$ & Não & 96,6 & 98,8 & 97,8 \\
\hline
\end{tabular}


Realizadas essas considerações, após o sorteio com base na população de 4.826 docentes, foi selecionada para a análise uma amostra de 350 docentes. Esse total equivale a 7,2\% da população da área de Psicologia, ficando a amostra caracterizada conforme as diversas variáveis detalhadas e descritas na Tabela 2.

\section{RESULTADOS E DISCUSSÃO}

Em primeira instância cabe ressaltar a evidente importância dos relatórios enviados pela Capes para fins dessa pesquisa. O confronto de fontes mencionado no corpo do texto parece sugerir que esses dados têm grande utilidade nas Comissões de Área, que possivelmente os complementa com informações adicionais e conhecimento da área que esses membros das comissões possuem. Por outro lado, o confronto também parece sugerir que nem sempre são completos os dados sobre publicações fornecidos pelos docentes para os relatórios enviados à Capes. Ainda pode sugerir que, posteriormente ao fornecimento dos dados aos programas, muitos docentes incluem em seus Currículos Lattes dados sobre suas publicações que não chegaram a ser informados quando da avaliação dos seus programas.

Segundo a faixa etária, a maior concentração de pesquisadores estava entre 45 e 49 anos de idade. As quatro instituições de ensino superior que possuíram mais representantes na amostra estavam localizadas em São Paulo: USP, UNESP, UNICAMP e PUC-SP. Demonstrando claramente uma concentração regional na amostra. A maioria da amostra realizou pós-doc após 2002, sendo $16 \%$ entre 1996 e 1999; 27\% entre 2000 e 2010 e 52\% após o ano 2010.

$\mathrm{Na}$ amostra, $46,2 \%$ dos pesquisadores foram do sexo masculino e $54,8 \%$ do sexo feminino. Registra-se também que, pelos dados, em 2016 havia 1,2 mil grupos de pesquisa, 3,3 mil linhas de pesquisa. De 2000 para 2016 houve crescimento de aproximadamente $254 \%$ nos grupos de pesquisa e de $368 \%$ no quantitativo das linhas de pesquisa. Esses dados caminham na mesma direção do quadro apontado por Macedo e Sousa (2010), não havendo diferenças significativas nesse quesito.

Entre os docentes juniores da Psicologia participantes da pesquisa, 26\% têm pósdoutorado, valor que pode ser considerado baixo por alguns, mas em um cenário otimista, mostra que esse caráter opcional e complementar que é típico do pósdoutorado é levado em consideração na área de Psicologia e o mesmo, corretamente, não está sendo valorizado como uma titulação adicional e/ou como uma etapa obrigatória para a carreira acadêmica.

Examinamos em seguida o local de pós-doutoramento, se no Brasil ou no exterior. Os dados mostraram que entre os recém-doutores o quadro é praticamente dividido, não se nota diferença expressiva, demonstrando aparentemente que não há prioridade pelos doutores juniores para a realização do pós-doutorado fora do país. No entanto esse perfil varia para $76,6 \%$ dos pós- 
doutorados sendo realizados no exterior, quando consideramos o estrato dos doutores seniores, com mais experiência na carreira (Tabela 1).

Pode-se ser observado como o pós-doutorado feito no exterior se distribuiu pelos países. Além do Brasil, país preferido por quase um terço dos que fizeram pós-doutorado em Psicologia, os outros principais países são a França (17\%) e Portugal (15\%), seguidos por Espanha, Estados Unidos e Grã-Bretanha (aproximadamente $7 \%$ cada um), vindo depois a Alemanha, a Argentina e o Canadá (menos de $5 \%$ cada um). Os demais países somados chegam a $4 \%$ da amostra.

Considerando a nota do programa de pós-graduação, de uma forma geral na Tabela 2, observa-se que, nos programas de maior avaliação, a proporção de seniores atuando é superior à de juniores. Nos programas de menor avaliação ocorre o inverso, isto é, há mais docentes juniores atuando.

O mesmo acontece em relação a publicações registradas em revistas de primeira linha, consideradas de alcance internacional, com maiores impactos e geralmente classificadas como A1 e A2 nos estratos do Qualis. A publicação nesses estratos mais elevados do Qualis é realizada, segundo os dados da pesquisa, por doutores seniores, sendo bastante superior o mesmo tipo de inserção quando comparado pelos juniores (Tabela 2).

Debruçando-se sobre os dados da amostra quanto ao local da realização do doutorado, conforme Figura 1, observa-se que não há diferenças expressivas entre os outputs em revistas de padrão ' $A$ ', em função do local da formação doutoral. Os doutores com formação integral no Brasil, os com formação plena no Exterior e os com formação sanduíche, ou seja, os doutores que concluíram doutorado no Brasil, mas com um período de estágio no exterior, todos eles possuem padrão e perfil de produção em revistas classificadas como " $A$ ", que são entre si equivalentes.

Esses dados da área de Psicologia da Figura 1 sustentariam a tese de Meneghini (1995), segundo a qual o doutorado pleno no exterior só deveria ser realizado em casos excepcionais, pois os que se titularam no exterior publicam em nível praticamente igual ao dos titulados no Brasil. No entanto, chama bastante a atenção que na área de Psicologia, o pós-doutorado parece anular ou compensar os efeitos da formação no exterior e fornece elementos à tese contrária, do pesquisador Meneghini (1995). 


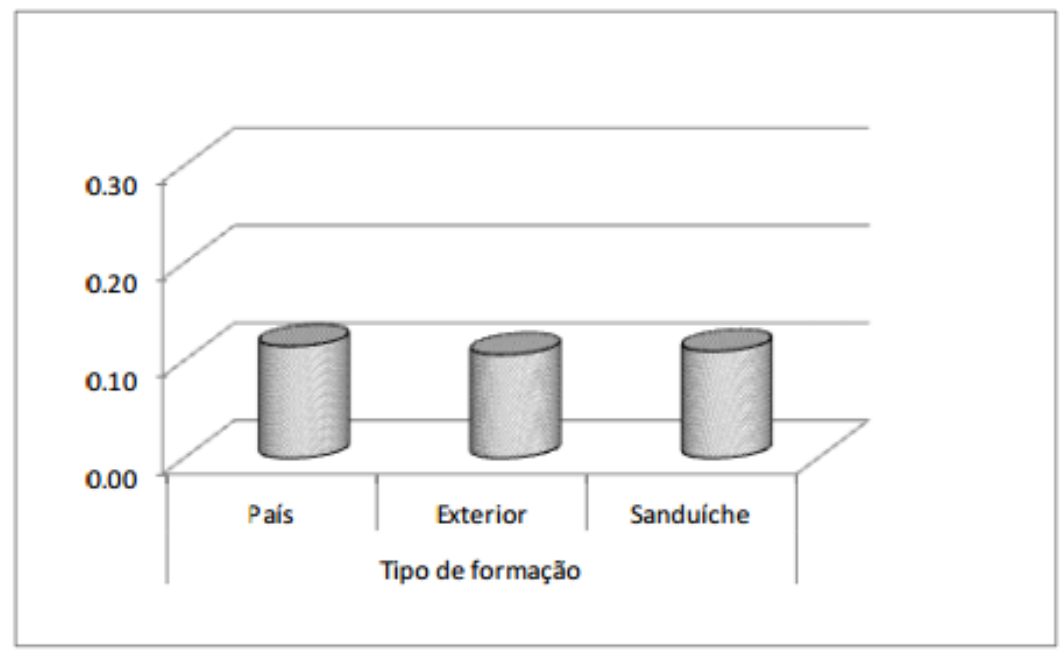

\section{Figura 1}

Médias anuais de artigos em periódicos de padrão 'A' por tipo de formação. Fonte: Dados da pesquisa

Pode ser observado na Figura 2, na área de Psicologia, o disposto vai ao encontro e corrobora a tese levantada em Castro e Porto (2012) em outras áreas do conhecimento, que aponta o pós-doutorado como tendo uma maior influência sobre revistas internacionais do estrato ' $\mathrm{A}$ '.

Diante desses dados da Psicologia, nos quais as médias de artigos em periódicos de padrão internacional são semelhantes entre si nos três tipos de formação (Figura 2), pode-se afirmar que estaria sustentada a ideia que para essa área, a melhor trajetória de formação seria a titulação no Brasil (para melhor inserção na realidade nacional) a posteriori com a opção pós-doutorado no exterior (para maior adequação/atualização dos trabalhos e métodos de pesquisas).

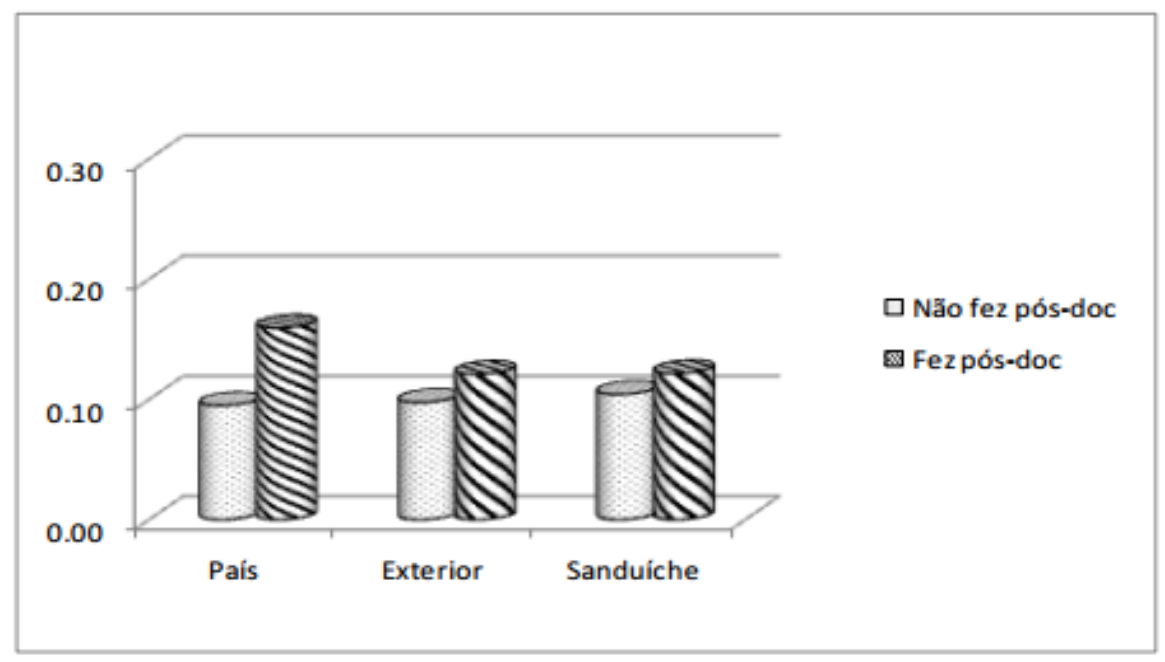

\section{Figura 2}

Médias anuais de artigos em periódicos de padrão 'A' por tipo de formação e a realização ou não do estágio pós-doutoral 
Confrontado o panorama da Figura 2 com o trazido pela Figura 3 nota-se que para a inserção da produção em periódicos de maior qualidade, o tipo de formação (Brasil vs. Exterior) não é a variável preditora, os dados sugerem que para o impulso nesse estrato de produção mais importante é sim o interstício, o qual podemos considerar, ou reforçá-lo, sendo a experiência na carreira como fundamental para a maior inserção em periódicos de nível ' $A$ '.

Na Figura 3 é possível observar as médias anuais de artigos em periódicos de padrão 'A' e pós-doutorado realizado controlado pelo nível de experiência do pesquisador, ou seja pelo interstício entre a conclusão do doutorado e a realização do pós-doc (interstício menor ou igual a cinco anos $=$ júnior, e o interstício maior que cinco anos = sênior). Nota-se uma diferença expressiva no que diz respeito à influência do pós-doutorado sobre a produção qualificada de doutores seniores, que salta de 0,059 artigos por ano, para 0,131 artigos por ano em mídia prestigiosa de padrão ' $A$ '.

Conforme a Figura 3, entre os juniores que seguiram pelo menos um pósdoutorado, a média anual de artigos em periódicos de padrão ' $A$ ' é mais elevada, mas segue a esse mesmo padrão, independentemente da realização ou não do pós-doutorado.

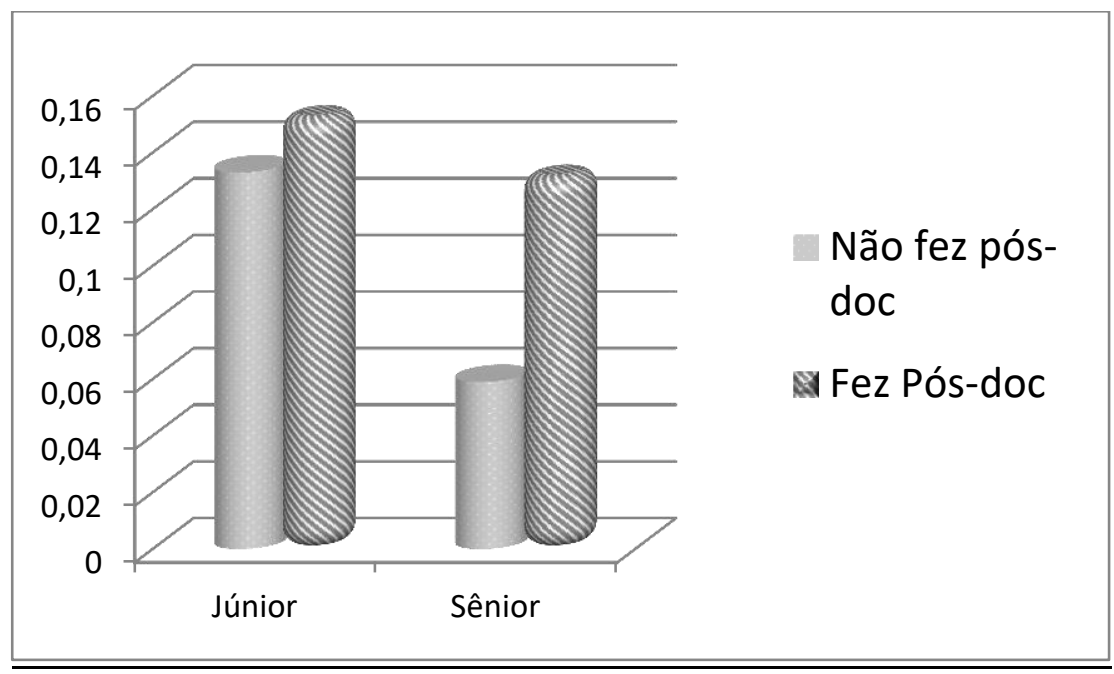

\section{Figura 3}

Médias anuais de artigos em periódicos de padrão ' $A$ ' em função da realização do pósdoutorado e o estágio na carreira docente.

Fonte: Dados da pesquisa

Como se observa na Figura 3, os recém-doutores tendem a possuírem uma produção com médias mais elevadas, mas essas médias são elevadas para ambos - os com e os sem pós-doutorado - não sendo o estágio pós-doutoral elemento diferenciador para o desempenho. No entanto, nota-se que o padrão da produção em mídia de maior qualidade, sofre uma diferenciação e um 
incremento expressivo especialmente quando verificado o efeito desse pósdoutorado realizado no contexto dos doutores seniores.

\section{Tabela 3}

Médias anuais de artigos em periódicos de padrão 'A', contrastado com a realização do pós-doutorado em função da avaliação do programa

\begin{tabular}{c|c|c|c}
\multirow{2}{*}{ Variável } & Categorias & \multicolumn{2}{c}{ Fez pós-doutorado } \\
\cline { 3 - 4 } & Não fez & Fez \\
\hline $\begin{array}{c}\text { Avaliação do programa } \\
\text { de vinculação do } \\
\text { docente }\end{array}$ & Menor avaliação (3 e 4) & 0,078 & 0,122 \\
\hline
\end{tabular}

Na Tabela 3 é possível observar a influência do pós-doutorado sobre a produção em mídia prestigiosa de padrão ' $A$ ', em função da relação com outras variáveis. Nota-se, por exemplo, que a nota do programa deriva mais da produção dos docentes do que em função do pós-doutorado. Isto é, o pós-doutorado contribui para o aumento da produção em mídia prestigiosa padrão ' $A$ ', mas não a ponto de alterar a nota do programa.

A média de produção dos programas com menores notas (3 e 4 na avaliação da Capes) sobe bastante com a realização do pós-doutorado pelos seus docentes, mas mesmo com o sobressalto, a média ainda fica abaixo da média de produção dos docentes sem pós-doutorado e que atuam em programas considerados de excelência (notas 5 e 6 na avaliação da Capes). A nota 7 não foi considerada em função do baixo coeficiente do grau de liberdade, vez que possuía pouca representatividade na amostra.

Debruçando-se sobre a Tabela 3 a motivação passou então à análise de demais dados da amostra, tendo como referência a participação em comitê editorial de periódico internacional, buscando verificar se o pós-doutoramento (como variável explicativa) influenciaria na participação nos referidos comitês em contraste com outras variáveis de controle; para isso foi utilizada a análise estruturada por meio de painéis (Tabela 4).

$\mathrm{Na}$ Tabela 4, Painel A, foi examinada a variável explicativa - fez ou não pósdoutorado, em relação direta à participação em comitê editorial de periódico internacional. No conjunto da amostra, os docentes que realizaram um estágio de pós-doutoramento têm participação mais elevada em comitê editorial de periódico internacional (4\%) do que aqueles que não fizeram o estágio (1\%). Porém, as diferenças não são significativas considerando-se $5 \%$ a margem de erro aceitável. Esses dados, com p-value > 0,05 não sustentam a questão levantada, de que o pós-doutoramento influenciaria na participação nos referidos comitês. 
Em seu Painel $B$, acrescentando a variável de controle - nível de experiência do docente, adicional em relação ao painel $A$; observa-se que entre os juniores a proporção de participação em comitê editorial de quem fez pós-doutoramento é quase o dobro da proporção de quem não fez, mas sem significância estatística, considerando uma margem de segurança de 90\% ( $p$-value > 0,10), podendo, dessa forma, esse registro ser uma característica de viés da amostra, mas não há como inferir que seja da população como um todo.

Entre os juniores, no Painel B observa-se que quem não fez pós-doutorado e participa de comitê representa 2,78\% da amostra, a proporção de participação para quem fez um pós-doutoramento é praticamente o dobro. Para os juniores, a diferença é significativa somente a $10 \%$. Isso significa que, entre os juniores com uma margem de segurança de $90 \%$, com $p$-value $<0,10$, pode-se afirmar que a realização de pós-doutorado afeta significativamente as chances de participar desses comitês de mídia prestigiosa de circulação internacional.

Na Tabela 4, Painel C, encontram-se os resultados para a participação em comitê editorial de periódico internacional por pós-doutoramento, controlando pelo nível de avaliação dos programas. Para os programas de menor avaliação, a proporção de participação nesses comitês dos que não fizeram pós-doutorado é de $0,7 \%$ e não participam os que fizeram pós-doutoramento; a diferença não é estatisticamente significativa.

Os docentes dos programas de maior avaliação (i.e. programas de excelência com nota 5 ou 6, e apenas para efeito de pesquisa, excetuando-se a nota 7) apresentam proporções de participação em comitê editorial superiores às dos docentes dos programas de menor avaliação, tenham eles feito ou não pósdoutorado ( $p$-value $=0,05$ ). Ou seja, a nota do programa e a participação em editorias de periódicos de primeira linha possuem uma relação direta, apesar de não ser possível traçar uma relação clara de causa e efeito. Trata-se de uma relação a se considerar.

Nos programas de maior avaliação, a proporção dos docentes que realizaram pós-doutoramento e participam de comitê editorial é quase o quádruplo da proporção dos que não fizeram pós-doutorado (3,78 maior), e essa diferença registrada é significativa, sendo possível de se afirmar com uma margem de segurança de $90 \%$ ( $p$-value $<0,10$ ). Isso significa que para os programas de excelência, a realização de pós-doutorado influencia na participação nesses comitês. 
Tabela 4

Participação em comitê editorial de periódico internacional, em função do pós-doutoramento e também deste controlado pela experiência do docente e pela avaliação do programa - em termos percentuais

\begin{tabular}{|c|c|c|c|c|c|}
\hline \multirow[t]{2}{*}{ Painéis } & \multirow[t]{2}{*}{$\begin{array}{l}\text { Variáveis } \\
\text { controle }\end{array}$} & \multirow[t]{2}{*}{$\begin{array}{l}\text { Variável } \\
\text { explicativa }\end{array}$} & \multicolumn{2}{|c|}{$\begin{array}{l}\text { Participa de Comitê } \\
\text { Editorial em periódico } \\
\text { internacional }\end{array}$} & \multirow[b]{2}{*}{$n$} \\
\hline & & & Não participa & Participa & \\
\hline \multirow[b]{2}{*}{ Painel A } & & Fez Pós-doutorado & $96,08 \%$ & $3,92 \%$ & 132 \\
\hline & - & $\begin{array}{l}\text { Não fez pós- } \\
\text { doutorado }\end{array}$ & $98,62 \%$ & $1,38 \%$ & 218 \\
\hline \multirow{4}{*}{ Painel B } & \multirow{2}{*}{ Júnior } & $\begin{array}{c}\text { Fez Pós- } \\
\text { doutorado(*) }\end{array}$ & $94,74 \%$ & $5,26 \%$ & 58 \\
\hline & & $\begin{array}{c}\text { Não fez pós- } \\
\text { doutorado }\end{array}$ & $97,22 \%$ & $2,78 \%$ & 108 \\
\hline & \multirow[b]{2}{*}{ Sênior } & Fez Pós-doutorado & $96,88 \%$ & $3,13 \%$ & 120 \\
\hline & & $\begin{array}{c}\text { Não fez pós- } \\
\text { doutorado }\end{array}$ & $100 \%$ & - & 64 \\
\hline \multirow{4}{*}{ Painel C } & \multirow{2}{*}{$\begin{array}{c}\text { Programas } \\
\text { com notas } \\
3 \text { e } 4\end{array}$} & Fez Pós-doutorado & $99,32 \%$ & $0,68 \%$ & 65 \\
\hline & & $\begin{array}{c}\text { Não fez pós- } \\
\text { doutorado }\end{array}$ & $100 \%$ & - & 178 \\
\hline & \multirow{2}{*}{$\begin{array}{l}\text { Programas } \\
\text { de } \\
\text { excelência }\end{array}$} & $\begin{array}{c}\text { Fez Pós- } \\
\text { doutorado(*) }\end{array}$ & $89,19 \%$ & $10,81 \%$ & 70 \\
\hline & & $\begin{array}{l}\text { Não fez pós- } \\
\text { doutorado }\end{array}$ & $97,14 \%$ & $2,86 \%$ & 37 \\
\hline
\end{tabular}

Nota. ${ }^{(*)}$ Diferenças significativas a $10 \%$

\section{CONSIDERAÇÕES FINAIS}

Resumindo os dados e os resultados encontrados, pode ser visto na área de Psicologia, um quadro em que as diferenças não corresponderam às nossas expectativas - afinal também somos pesquisadores - algo que o cenário global do Pós-doutorado da área de Psicologia, lembra o cenário apontado por Castro e Porto (2016): Pós-doutorado [Na Psicologia]? Trata-se de um "copo meio cheio ou meio vazio"? 
Em alguns momentos nota-se que não são encontradas diferenças significativas, o que de certa forma mostra que o pós-doutorado não é solução para tudo e não desenha um caminho "líquido e certo", como um aperfeiçoamento em que traga em todos os momentos um alto retorno no que tange a outputs plenamente visíveis, para o desejado no sistema de pós-graduação.

Por outro lado, é preciso registrar que esse caráter morno predomina no contexto geral. Entretanto, ao serem efetuadas análises de uma forma mais aprofundada, observa-se que os resultados tornam-se mais expressivos em alguns aspectos: entre os docentes que atuam em programas menos bem avaliados (notas 3 e 4 segundo avaliação da Capes), com margem de segurança de $90 \%$ o efeito do pós-doutorado não mostra-se expressivo no que diz respeito a abrir possibilidades adicionais como começar a participar de comitês editoriais que antes não participavam; registrando-se que a influência do pós-doutorado muda de expressão quando são analisados os programas de excelência (notas 5 e 6 , segundo avaliação da Capes), nesses programas os docentes que realizam pósdoutorado possuem maior produção e mais participação em comitês de "revistas de ponta", do que os docentes que não realizaram o estágio de pósdoutoramento.

O tipo de formação doutoral - se tradicional ou sanduíche - não parece influir sobre o desempenho dos docentes, o que pode ser interpretado como um bom sinal ao reforçar que os programas de doutorado no país de fato estão consolidados, não estão defasados no que diz respeito à sua formação em relação aos doutoramentos do exterior. Mas, isso é apenas uma sinalização, e não anula a possibilidade de verificar-se essa questão em estudos futuros para que se possa aprofundar em específico a questão do doutorado sanduíche.

No que tange aos dados dos outputs dos titulados no País têm média até um pouco superior à dos outros tipos de titulação, como o doutorado pleno e os que seguiram doutorado sanduíche e isso quando confrontado com o pósdoutorado, traz um cenário muito próximo do encontrado por Castro e Porto (2008). Ou seja, o par doutorado pleno no exterior - pós-doutorado no exterior, continua trazendo retornos em termos de outputs registrados no sistema Lattes.

Como resultado mais expressivo da pesquisa, essa exploração inicial dos dados da área de Psicologia contribuiu um pouco para o melhor entendimento da área, no que se refere às médias de publicação de artigos de padrão ' $A$ '. $E$, uma contribuição foi dada pelo pós-doutoramento, que inicialmente não se mostrava relevante quanto à variável dependente considerada, mas que com o controle pelo nível de experiência do docente revelou-se importante: entre seniores, (carreiras mais desenvolvidas e com distância maior do tempo de conclusão de doutoramento), o pós-doutoramento mostrou ser um fator diferenciador das médias de publicação.

A irrelevância do pós-doutorado entre juniores (i.e., doutores com menos de cinco anos de conclusão do doutorado) fica sem justificativa aparente. Mas, não 
há como não observar que se trata de uma primeira pesquisa sobre o tema na área de Psicologia, devendo, portanto, tal questão ser buscada também em estudos posteriores. Do ponto de vista dos aspectos a serem considerados na presente tese que se levanta, os dados da Psicologia no sentido transversal de ser uma área do conhecimento e que, perpassa por diversas instituições, nota-se que esse fenômeno do pós-doutorado traz impactos mais positivos para os pesquisadores seniores e ser quase irrelevante para os recém-doutores, também foi verificado por Castro et al. (2013) na USP, nas grandes áreas de Biológicas, Exatas, Engenharias e Saúde e também por Calvosa et al. (2011), em uma verificação censitária na UFF.

Diante das políticas atuais de contingenciamento do governo federal, estudos como este sinalizam e fornecem elementos com dados robustos para que, inclusive, críticas sejam realizadas às políticas, podendo por exemplo subsidiar a manutenção das bolsas de pós-doutorado para pesquisadores seniores. Ressaltase que os direcionamentos estão altamente instáveis, pois somente à Coordenação de Aperfeiçoamento de Pessoal de Nível Superior - CAPES, alterou as suas políticas de contingenciamento diversas vezes em 2019 e anuncia agora um novo modelo de distribuição de bolsas que passa a valer para 2020, em prol da maior estabilidade.

Convém registrar um aspecto importante que diferencia essa pesquisa dos dois estudos anteriores citados, em que se pese o resultado ser próximo no sentido da sua interpretação. Ou seja, o pós-doutorado indicando ser um estágio de aperfeiçoamento com resultados mais promissores para os doutores seniores. Deve-se registrar que Calvosa et al. (2011) e Castro et al. (2013) trabalham com uma produção de uma forma ampla, estudando produções bibliográficas diversas como Livros, publicação em anais de congressos, etc. e também todos os extratos de qualidade do Qualis - A, B e C, enquanto neste estudo foi analisada uma produção mais focal, registrando-se o efeito sobre a produção no que tange especificamente à produção de artigos em revistas de padrão ' $A$ '.

Nesse quesito, os dados da pesquisa mais do que meramente corroborar os estudos acerca do interstício (Calvosa et al., 2011; Castro et al., 2013), mostra especialmente também que na área de Psicologia, notadamente para os doutores seniores o pós-doutorado, torna-se mais válido - no que diz respeito aos seus outputs; e, além disso a notícia promissora é que, sobretudo, esse output possui um incremento no nível mais alto do estrato dos periódicos, considerados A1 ou A2 conforme a avalição Qualis da Capes.

Um outro aspecto positivo é que esse incremento em publicações de padrão 'A' traz ainda um ponto relevante no que diz respeito à potencialização do caráter público e de disseminação dos trabalhos de pesquisa. Quase que a totalidade dessas revistas se encontra atualmente classificada como $\mathrm{A} 1$ e algumas outras como A2, ambas quase que em totalidade encontram-se, integralmente, disponibilizadas tanto no portal de Periódicos da Capes 
(www.periodicos.capes.gov.br), quanto no portal Scielo (http://www.scielo.br/), ambos com acesso on-line gratuito. Isso facilita a disponibilidade desse conhecimento para os professores, estudantes de pós-graduação e a comunidade usuária das bibliotecas nas diversas Instituições de Ensino Superior nacionais.

A área de Psicologia se aproximou muito dos resultados do pós-doutorado encontrados nas Hard Sciences. Em Castro e Porto (2010), áreas aparentemente heterogêneas como Biológicas e Engenharias, por exemplo, apresentaram resultados muitos semelhantes. No entanto há que se frisar, que na área de Humanidades a diversidade é ainda maior e a Psicologia seria a primeira a ser investigada nesse âmbito. Será que os resultados encontrados teriam mais a ver com o pós-doutorado em si do que com a área do conhecimento em particular? Talvez sim, mas por enquanto parece cedo afirmar, algo nesse sentido, pois mais pesquisas seriam necessárias, em diferentes áreas.

Em suma, pelo que sugerem os resultados, a exploração adicional da Psicologia não trouxe elementos para compreensão dessa área a ponto de diferenciá-la das Hard Sciences, já estudadas pela literatura aqui citada acerca do estágio pósdoutoral e seus outputs - e traz a marca do cenário positivo para os professores seniores da área, podendo ser um diferencial de carreira para esses profissionais ao cotejar-se os que realizaram, com os que não realizaram, estágio pósdoutoral; destacando-se ainda mais para os docentes do quadro dos programas melhor avaliados pela Capes.

Enquanto pesquisa trazendo mais perguntas que respostas, espera-se que investigações futuras possam contribuir para responder às questões que ficaram sem respostas no presente estudo, pois certamente trata-se de um campo de pesquisa praticamente em aberto, recente e bastante promissor.

\section{REFERÊNCIAS}

Bonaccorsi, A., \& Daraio, C. (2003). Age effects in scientific productivity: The case of the Italian National Research Council (CNR). Scientometrics, 58(1), 49-90. doi: 10.1023/A:1025427507552

Calvosa, M. V. D., Repossi, M. G., \& Castro, P. M. R. (2011). Avaliação de resultados da capacitação docente: O Pós-doutorado na Universidade Federal Fluminense sob a ótica da produção científica e bibliográfica. Revista da Avaliação da Educação Superior, 16(1), 99-122. doi: 10.1590/S1414-40772011000100006

Castro, P. M. R (2017). Influência do pós-doutorado sobre produção científica da pós-graduação: O caso da USP. Saarbrücken: Novas Edições Acadêmicas.

Castro, P. M. R., \& Porto, G. S. (2008). Retorno ao exterior vale a pena? A questão dos estágios pósdoutorais sob a perspectiva da produção em C\&T. Organizações \& Sociedade, 15(47), 155 173. doi: 10.1590/S1984-92302008000400009

Castro, P. M. R., \& Porto, G. S. (2010). Análise exploratória sobre a mensuração de resultados da capacitação via estágios pós-doutorais: Heterogeneidade entre grandes áreas do conhecimento?. Revista de Administração (RAUSP), 45(1), 43-56. doi: 10.1016/S00802107(16)30508-8 
Castro, P. M. R., \& Porto, G. S. (2012). Avaliação de resultados da capacitação via estágios pósdoutorais: Breves notas sobre a produção científica em periódicos. Ensaio: Avaliação e Políticas Públicas em Educação, 20(74), 51-72. doi: 10.1590/S0104-40362012000100004

Castro, P. M. R., \& Porto, G. S. (2016). Copo meio cheio ou copo meio vazio? Estágio pós-doutoral, face exposta, revisão crítica e agenda de pesquisa. Educação em Revista, 32(1), 159-184. doi: 10.1590/0102-4698140410

Castro, P. M. R., Porto, G. S., \& Kannebley, S. (2013). Pós-doutorado, essencial ou opcional? Revista da Avaliação da Educação Superior, 18(3), 773-801. doi: 10.1590/S141440772013000300013

Coraiola, D. M., Baratter M. A., Takahashi, A. R. W., \& May, M. R. (2016). Pós-doutorado na formação dos docentes de programas de pós-graduação em administração no Brasil - Perfil e configuração. Administração: Ensino e Pesquisa, 14(4), 725-758. doi: 10.13058/raep.2013.v14n4.50.

Macedo, E., \& Sousa, C. P. (2010). A pesquisa em educação no Brasil. Revista Brasileira de Educação 15(43), 166-202. doi: 10.1590/S1413-24782010000100012.

Meneghini, R. (1995) Performance of Brazilian scientists and the pattern of scientific training: A comparison between physicists and chemists. Ciência e Cultura, 47(2), 45-49.

Mueller, S. P. M. (2006). A comunicação científica e o movimento de acesso livre ao conhecimento. Ciência da Informação, 35(2), 27-38. doi: 10.1590/S0100-19652006000200004

Trigueiro, M. G. (2001). A formação de cientistas: Necessidades e soluções. In M. Baumgartem (Ed.) A era do conhecimento: Matrix ou Ágora? (pp. 61-70). Porto Alegre, RS: UFRGS.

Witter, G. P. (1996). Catálogo de publicações dos docentes 1990/1994. Campinas, SP: Editora PUCCampinas.

\section{CONFLITOS DE INTERESSES}

Não há conflitos de interesses.

\section{SOBRE OS AUTORES}

Marcello Vinicius Dória Calvosa é graduado em administração de empresas e administração pública, ambas as habilitações obtidas pela Universidade Federal Rural do Rio de Janeiro (UFRRJ), mestre em gestão e estratégia de negócios pela UFRRJ e doutor em administração pela Universidade de São Paulo (USP), com foco em desenvolvimento humano, planejamento estratégico pessoal e gestão de carreiras. Atua como Professor Associado e Coordenador de Projetos e de Extensão no DCAdUFRRJ, Coordenador de Área do CEDERJ e da UAB, Líder do Grupo de Pesquisas GECAPEP e Coordenador do Programa de Extensão DEGECAR. Atualmente, desenvolve linhas de investigação do impacto do pós-doutorado, de valores pessoais e desenvolvimento e gestão de carreira. E-mail: mvcalvosa@yahoo.com.br 